\title{
Purification of full-length human Pregnane and Xenobiotic Receptor: polyclonal antibody preparation for immunological characterization
}

\author{
Mallampati SARADHI, Biji KRISHNA, Gauranga MUKHOPADHYAY, Rakesh K TYAGI* \\ Special Centre for Molecular Medicine, Jawaharlal Nehru University, New Delhi 110067, India
}

\begin{abstract}
Pregnane and Xenobiotic Receptor (PXR; or Steroid and Xenobiotic Receptor, SXR), a new member of the nuclear receptor superfamily, is thought to modulate a network of genes that are involved in xenobiotic metabolism and elimination. To further explore the role of PXR in body's homeostatic mechanisms, we for the first time, report successful prokaryotic expression and purification of full-length PXR and preparation of polyclonal antibody against the whole protein. The full-length cDNA encoding a 434 amino acids protein was sub-cloned into prokaryotic expression vector, pET-30b and transformed into $E$. coli BL21(DE3) cells for efficient over expression. The inclusion body fraction, containing the expressed recombinant protein, was purified first by solubilizing in sarcosine extraction buffer and then by affinity column chromatography using Ni-NTA His-Bind matrix. The efficacy of anti-PXR antibody was confirmed by immunocytology, Western blot analysis, EMSA and immunohistochemistry. The antibody obtained was capable of detecting human and mouse PXR with high specificity and sensitivity. Immunofluorescence staining of COS-1 cells transfected with human or mouse PXR showed a clear nuclear localization. Results from immunohistochemistry showed that level of PXR in liver sections is immunologically detectable in the nuclei. Similar to exogenously transfected PXR, Western blot analysis of cell extract from HepG2 and COLO320DM cells revealed a major protein band for endogenous PXR having the expected molecular weight of $50 \mathrm{kDa}$. Relevance of other immunodetectable bands with reference to PXR isoforms and current testimony are evaluated. Advantages of antibody raised against full-length PXR protein for functional characterization of receptor is discussed and its application for clinical purposes is envisaged.
\end{abstract}

Keywords: Pregnane and Xenobiotic Receptor, Steroid and Xenobiotic Receptor, prokaryotic expression, polyclonal antibody, isoforms.

\section{INTRODUCTION}

Pregnane and Xenobiotic Receptor (PXR; or Steroid and Xenobiotic Receptor, SXR), is a relatively new member of the nuclear receptor superfamily. PXR (NR1I2), like other ligand-induced members of the superfamily, executes transcription functions by modulating a network of genes that are involved in xenobiotic metabolism and elimination [1-6]. A diverse range of endogenous metabolites, clinical drugs, xenobiotics that can act as ligands to PXR, has attracted profound interest in this

*Correspondence: Rakesh K TYAGI

Tel: +91-11-2671-7544;Fax: +91-11-2671-7586;

E-mail: rkt2300@mail.jnu.ac.in

Request for PXR antibody described in this paper should be made to the correspondence. receptor. Being a relatively newly discovered receptor, attempts from diverse laboratories are in progress to characterize this receptor and understand its molecular mechanism of actions, both, in context to its physiological significance and clinical importance. In recent studies, using Northern blotting and RT-PCR analysis, PXR has been detected in various tissues, being relatively higher in the liver, small intestine and colon; and, low levels in the skeletal muscle, stomach, testes, trachea, kidney, adrenal gland and thyroid gland $[3,7]$. Even though PXR was not detected in normal endometrium it was shown to be expressed in the endometrium of patients who underwent medication with oral contraceptives [8]. Recently, PXR was also reported to be expressed in the breast cancer [9] and endometrial cancer tissues [8] implying its possible significance in cancer.

Cytochrome p450 (CYP), a family of heme-proteins, 
have been known for long to perform the function of drug and xenobiotic metabolism. However, the emerging fact that some of the critical family members of CYP (CYP3A) are under the regulation of PXR has attracted renewed interest in this area. PXR-CYP3A pathway appears to play a key role in the intratumoral metabolism of steroid hormones, which are involved in the growth and development of cancerous tissues. Moreover, PXR mediated expression of P-glycoprotein and CYP3A genes might also be involved in enhanced drug clearance and eventual acquisition of resistance to anti-cancerous drugs $[10,11]$. Therefore, probing an investigation into the detailed functional aspects of PXR in several normal and cancerous cells necessitated the need for development of highly specific and well-characterized antibodies for PXR. Here, we report for first time, a successful expression of full-length PXR protein, development and characterization of polyclonal antiserum against our purified PXR preparation. Ideally, these antibodies should be useful in, hitherto controversial, immunocytochemical localization of the PXR protein in normal and malignant tissues and cultured cells; identification of the proteins that interact with PXR to mediate its cellular functions; immunoprecipitation of PXR expressed in cultured cells etc. In future, these antibodies can also serve as a useful tool in studies related to PXR modification, such as phosphorylation or mutagenesis. Their application for clinical purposes, in detecting the level of PXR expression in normal and tumour tissues as a prognostic molecular marker, is envisaged.

\section{MATERIALS AND METHODS}

Restriction endonucleases and ligase were obtained from New England Biolabs (Beverly, MA, USA). Cell culture DMEM / RPMI media, fetal bovine serum (FBS) and other mammalian cell culture reagents were procured from Hyclone (Logan, Utah, USA). HRPconjugated anti-rabbit secondary antibodies raised in goat were from Bio-Rad, (Hercules, USA). Ni-NTA His-Bind matrix was a product from Qiagen (Valencia, USA). Protein concentrations were determined using CB-X protein assay kit (Genotechnology, St. Louis, USA). Rabbits and mice were maintained in the central animal house, a core facility for Jawaharlal Nehru University, New Delhi, India. All other chemicals (unless otherwise mentioned) were obtained from Sigma Chemicals Co. (St. Louis, MO, USA).

\section{Plasmids}

Mammalian expression vectors for human PXR, pCMXPL2hSXR and pSG5-hPXR, were kindly provided by Dr. RM EVANS (Salk Institute, La Jolla, CA) and Dr. SA KLIEWER (University of Texas Southwestern Medical Center, Dallas, USA). Mouse PXR plasmids (pSG5-mPXR, pCDNA-mPXR) were generous gift from Dr. Kliewer and Dr. M NEGISHI (National Institute of Health, North Carolina, USA). In the text untagged human PXR is referred as hPXR and the mouse PXR as mPXR. We cloned the full-length cDNA for hPXR between $N c o$ I and Bam HI restriction sites of pET$30 \mathrm{~b}$ (Novagen) and designated it as pET-PXR. When expressed in $E$. coli BL21(DE3) the recombinant PXR was expressed as a fusion protein having the $\mathrm{N}$-terminal His-tag sequence.

\section{Prokaryotic expression and purification of full length PXR}

E. coli BL21 cells, transformed with the prokaryotic expression plasmid, pET-PXR, were cultured in presence of kanamycin $(30 \mu \mathrm{g} /$ $\mathrm{ml}$ ) in $\mathrm{LB}$ medium with vigorous shaking at $37^{\circ} \mathrm{C}$ until an $\mathrm{OD}_{600}$ of 0.4 to 0.6 was attained. The expression of recombinant PXR was induced by addition of $0.1 \mathrm{mM}$ isopropyl-1-thio-D-galactopyranoside (IPTG) and further incubation at $30^{\circ} \mathrm{C}$ for $3 \mathrm{~h}$. Cells were harvested by centrifugation at $4000 \times \mathrm{g}$ for $15 \mathrm{~min}$ at $4^{\circ} \mathrm{C}$ in a Beckman (model J2-21) centrifuge. The cell pellets were re-suspended in lysis buffer [50 mM Tris, pH 8.9, $100 \mathrm{mM} \mathrm{NaCl}, 1 \mathrm{mM}$ EDTA, $100 \mu \mathrm{g} / \mathrm{ml}$ lysozyme, $100 \mu \mathrm{g} / \mathrm{ml}$ phenylmethyl sulfonyl fluoride (PMSF) and 1 $\mu \mathrm{g} / \mathrm{ml}$ each of pepstatin, leupeptin and aprotinin, and further incubated at $4^{\circ} \mathrm{C}$ for $1 \mathrm{~h}$. There after the cells were sonicated and centrifuged at $11,000 \times \mathrm{g}$ for $15 \mathrm{~min}$, and the pelleted fractions containing inclusion bodies were incubated with urea extraction buffer $(50 \mathrm{mM}$ Tris, $\mathrm{pH} 8.9,100 \mathrm{mM} \mathrm{NaCl}, 1 \mathrm{mM}$ EDTA, $8 \mathrm{M}$ Urea, $1 \mathrm{mM} \beta$ mercapto-ethanol and protease inhibitors as mentioned above) at RT for $1 \mathrm{~h}$ and centrifuged at $11,000 \times \mathrm{g}$ for $15 \mathrm{~min}$. Urea extracted pellet was incubated with sarcosine extraction buffer $(50 \mathrm{mM}$ Tris, $\mathrm{pH} 8.9$, $100 \mathrm{mM} \mathrm{NaCl}, 1.0 \% \mathrm{~N}$-lauroylsarcosine, $1 \mathrm{mM} \beta$-mercaptoethanol and protease inhibitors) at RT for $1 \mathrm{~h}$ and again centrifuged at 11 , $000 \times \mathrm{g}$ for $15 \mathrm{~min}$. In the supernatant sarcosine concentration was readjusted to $0.3 \%$ and incubated with $0.5 \mathrm{ml}$ of Ni-NTA His-Bind matrix with gentle agitation at room temperature for $1 \mathrm{~h}$ according to the manufacturer's instructions. The matrix was then loaded on to a column and washed with washing buffer ( $100 \mathrm{mM}$ sodium phosphate, pH 8.0, $300 \mathrm{mM} \mathrm{NaCl}, 0.3 \% \mathrm{~N}$-lauroylsarco-sine, $1 \mathrm{mM} \beta$ mercaptoethanol and protease inhibitors). The matrix-bound protein was then eluted with elution buffer $(100 \mathrm{mM}$ sodium phosphate, $\mathrm{pH} 8$. $0,150 \mathrm{mM} \mathrm{NaCl}, 0.3 \% \mathrm{~N}$-lauroylsarcosine, $200 \mathrm{mM}$ imidazole, $1 \mathrm{mM}$ $\beta$-mercaptoethanol and protease inhibitors), and five fractions of 0.5 $\mathrm{ml}$ each were collected. The eluted proteins recovered in different fractions were analyzed by SDS-PAGE and coomassie brilliant blue staining.

\section{Production of polyclonal antiserum against PXR}

Immunization of New Zealand White rabbit was performed with homogenized polyacrylamide gel slices containing purified protein PXR antigen. Briefly, eluted fractions with protein were pooled and a protein mixture containing $250 \mu \mathrm{g}$ of PXR protein antigen was electrophoresed through 10\% SDS-PAGE and the gel was soaked in ice-cold $0.1 \mathrm{M} \mathrm{KCl}$ for 5 to $15 \mathrm{~min}$. Whitish protein band for PXR (corresponding to $\sim 55 \mathrm{kDa}$ ) against a clear gel background were excised with a scalpel and homogenized in $500 \mu 1$ of PBS. To reconfirm the recovery and purity of PXR protein, a fraction of sample obtained from homogenized gel pieces after over night incubation in sample buffer was electrophoresed on 10\% SDS-PAGE. Rabbit was immunized subcutaneously at four different sites with $200 \mu \mathrm{g}$ of PXR antigen after suspending in equal volume of complete Freund's adjuvant. Three weeks later, the rabbit was injected with $200 \mu \mathrm{g}$ of PXR with Freund's incomplete adjuvant as booster injections. Overall three booster doses were administered at $3 \mathrm{w}$ intervals. Two weeks after the final booster dose, serum was separated from the blood collected from rabbit's ear vein and stored in $0.1 \%$ sodium azide at $-20^{\circ} \mathrm{C}$. Other than the pre-immune serum, small aliquots of sera 
samples at every step of immunization were also collected. When required, a small aliquot of PXR antiserum and preimmune serum was purified using protein-A-sepahrose CL-4B (Sigma).

\section{Maintenance of cell-lines and transient transfections}

Cell lines used in this study were COS-1 (kidney cell line from African green monkey), HepG2 (human liver cell line) and COLO320DM (human colon carcinoma cell line). These ATCC cell lines were obtained from National Centre for Cell Science repository (Pune, India). COS-1 and HepG2 cells were grown in Dulbecco's modified Eagle's medium (DMEM) while COLO320DM cells were grown in RPMI, supplemented with $10 \%$ fetal calf serum, $100 \mu \mathrm{g} / \mathrm{ml}$ penicillin and $100 \mu \mathrm{g} / \mathrm{ml}$ streptomycin (complete medium) according to ATCC recommendation. The cells were cultured in a humidified incubator maintained at $5 \% \mathrm{CO}_{2}$ and $95 \%$ air atmosphere at $37^{\circ} \mathrm{C}$.

Transient DNA transfections in COS-1 cells were performed in $35 \mathrm{~mm}$ petridishes using Escort III reagent. For each transfection, $500 \mathrm{ng}$ of hPXR or mPXR was used. Following the transfection period of 12-15 h, the cells were supplemented with fresh complete medium and further incubated at $37^{\circ} \mathrm{C}$ for 0 to $40 \mathrm{~h}$ depending on experimental requirements.

\section{Fluorescence imaging}

Immunocytochemistry: For indirect immunodetection, COS-1 cells were cultured over sterile glass cover slips and transfected with 500 ng of hPXR or mPXR expression plasmid by Escort III transfection reagent and grown for $24 \mathrm{~h}$ following transfection. After transfection and expression period, the cells were washed thrice with phosphate buffered saline (PBS) and the cells were fixed with chilled methanol $\left(-20^{\circ} \mathrm{C}\right)$ for $15 \mathrm{~min}$ on ice. Following fixation, the cover slips were washed twice with PBS, air dried and kept at $-20^{\circ} \mathrm{C}$ for $1 \mathrm{~h}$ or stored till further use. For immunodetection, the cells were incubated in a humidified chamber for $30 \mathrm{~min}$ and blocked in $1 \%$ bovine serum albumin (BSA) in PBS for $30 \mathrm{~min}$. The cells were then incubated with PXR polyclonal antiserum or preimmune serum $(1: 500)$ at $4^{\circ} \mathrm{C}$ for 12-16 h. Following three washes with PBS, the cells were further incubated with Cy3-conjugated goat anti-rabbit IgG (Sigma) for $1 \mathrm{~h}$ at room temperature. To remove unbound antibodies, the cells were washed three times with PBS and the cover slips were mounted on glass slides and visualized by fluorescence microscopy. Hoechst 33342 was co-incubated with the secondary antibody to facilitate the visualization of the nuclei. The fluorescent cells were viewed through a Nikon upright fluorescence microscope model 80i equipped with water immersion objectives and connected to cooled CCD digital camera (model Evolution VF, Media cybernatics, USA). Images were captured and analyzed with Image ProPlus version 5.0 software (Media cybernatics, USA). The images were processed using standard image processing techniques.

\section{Electrophoretic mobility shift assays (EMSA)}

Preparation of whole cell lysate: COS-1 cells were transiently transfected with hPXR and $24 \mathrm{~h}$ after expression period, cells were washed thrice with PBS and scraped manually using a rubber policeman. Fifty microlitres of lysis buffer (20 mM HEPES-KOH pH 7.8, $0.5 \mathrm{mM}$ magnesium acetate, $1 \mathrm{mM}$ dithiothreitol, $1 \mathrm{mM}$ PMSF and $0.01 \%$ Nonidet P-40) was added to the cell pellet and incubated on ice for 10-20 min with occasional mixing. To this mixture, $5 \mathrm{M} \mathrm{NaCl}$ was added to a final concentration of $0.4 \mathrm{M}$ and incubated further for $10 \mathrm{~min}$ and then sonicated on ice. The sonicated sample was centrifuged at $4,100 \times \mathrm{g}$ for $10 \mathrm{~min}$ at $4^{\circ} \mathrm{C}$. The supernatant was collected, frozen in liquid nitrogen and stored at $-80^{\circ} \mathrm{C}$ till further use.

In EMSA, $1 \mu \mathrm{g}$ of total protein was incubated with $0.5 \mathrm{ng}$ of $3^{\prime}$ Klenow end labeled 30 bp double stranded oligonucleotide probe. The binding reaction was carried out in a volume of $20 \mu \mathrm{l}$ containing $20 \mathrm{mM}$ HEPES-KOH, pH 7.8, $50 \mathrm{mM} \mathrm{KCl,} 1 \mathrm{mM}$ DTT, $0.01 \%$ Nonidet P-40, $6 \%$ glycerol and $1 \mu \mathrm{g}$ of polydI/dC at room temperature for $30 \mathrm{~min}$. Where appropriate, competitor oligonucleotides at a 100,150 or 200 fold molar excess were included in the binding reaction. For determining the specificity of the antibody to PXR-DNA complex, binding reaction mixture containing the probe and the cell extract was pre-incubated at room temperature for $15 \mathrm{~min}$. After preincubation, $2 \mu \mathrm{g}$ of purified immnuoglobulins to PXR or control immunoglobulins were added to the binding reaction mixture and further incubated for $15 \mathrm{~min}$ at room temperature. Complexes thus formed were electrophoresed through $5 \%$ polyacrylamide gel in $1 \times$ TBE ( $89 \mathrm{mM}$ Tris-base, $89 \mathrm{mM}$ boric acid, $2 \mathrm{mM}$ EDTA) at room temperature. The gels were dried and auto-radiographed overnight at $-70^{\circ} \mathrm{C}$. The oligonucleotides sequences (sense strand) shown below were used either as radio-labeled probes or cold competitors. Letters shown in bold represent the corresponding bases replaced in mutant CYP3A4 ER6.

CYP3A4 ER6: 5'- GAT CCA TAT GAA CTC AAA GGA GGT CAG TGG-3'

CYP3A4 ER6 mutant: 5'- GAT CCA TAT GTT CTC AAA GGA GAA CAG TGG-3'

\section{RNA isolation and RT-PCR}

COS- 1 and COLO cells were cultured up to $80 \%$ confluency and harvested by scraping with a rubber policeman. Total RNA from COS-1 and COLO cells were isolated using TriReagent (Sigma) according to the manufacturer's instructions. Contaminating genomic DNA was removed by treatment with RNase-free DNase I (Takara). $5 \mu \mathrm{g}$ of total RNA was reverse-transcribed using RevertAid first strand cDNA synthesis kit (Fermentas). PCR amplification of PXR cDNA was performed as per standard methods using radio-labelled nucleotide $\left[\alpha-{ }^{32} \mathrm{P}\right]$ dATP. $5 \mu$ of reverse transcription mixture was amplified by PCR in a volume of $25 \mu \mathrm{l}$, in the presence of $2.5 \mu \mathrm{Ci}$ of [a- ${ }^{32} \mathrm{P}$ ] dATP $(1500 \mathrm{Ci} / \mathrm{mmol}), 10 \mu \mathrm{M}$ dATP, $100 \mu \mathrm{M}$ dTTP, 100 $\mu \mathrm{M}$ dGTP, $100 \mu \mathrm{M}$ dCTP, $0.2 \mu \mathrm{M}$ concentration of each forward and reverse primer and $2.5 \mathrm{U}$ of Taq DNA polymerase (New England Biolabs). Each PCR consisted of $5 \mathrm{~min}$ at $94^{\circ} \mathrm{C}$, followed by 30 cycles of $45 \mathrm{~s}$ at $94^{\circ} \mathrm{C}, 30 \mathrm{~s}$ at $60^{\circ} \mathrm{C}$ and $30 \mathrm{~s}$ at $72^{\circ} \mathrm{C}$. PCR products were ethanol precipitated and were resolved on $5 \%$ polyacrylamide gel. Following electrophoresis, the gel was dried and autoradiographed. In parallel, $\beta$-actin cDNA was amplified and PCR products were resolved on $2 \%$ agarose gel stained with ethidium bromide and documented with Gel-Doc system (Alpha Innotech Corp., USA). The following primers were used in cDNA amplification that generated an amplified fragment size of $410 \mathrm{bp}$ for PXR and an amplified fragment size of 614 bp for $\beta$-actin.

PXR forward primer: 5'-GAG GAC ACA GAG TCT GTT CCT GGA AAG CCC-3';

PXR reverse primer: 5'-GCT CCC TGA TCA TCA TCC GCT GCT CC-3';

$\beta$-actin forward primer: 5'-CGA GCA CGG CAT CGT CAC CAA C-3';

$\beta$-actin reverse primer: 5'-GTG GAT GCC ACA GGA CTC CAT GCC-3' 


\section{Western blot analysis}

The pET-PXR transformed, $0.1 \mathrm{mM}$ IPTG induced and uninduced (control) E. coli $\mathrm{BL} 21$ cells were incubated at $30^{\circ} \mathrm{C}$ for $3 \mathrm{~h}$ to overexpress the recombinant protein. Equal number of bacterial cells were then pelleted by centrifugation at $4,000 \times \mathrm{g}$ for $15 \mathrm{~min}$ and lysed in SDS-PAGE sample buffer for Western blotting.

COS-1 cells were transfected with one of the following plasmids: hPXR or mPXR by Escort III reagent and allowed to express protein that varied between 0 to $40 \mathrm{~h}$ after transfection depending on experimental requirement. Following transfection period the cells were lysed in the SDS-PAGE sample buffer and used for blotting.

For preparing the PXR-enriched fraction, protein extract from COS-1, HepG2 and COLO cells was prepared by re-suspending the cell pellet in lysis buffer (50 mM Tris, pH 7.4, $150 \mathrm{mM} \mathrm{NaCl}, 5 \mathrm{mM}$ EDTA, $1 \%$ Triton X-100 and protease inhibitors cocktail as mentioned above) and incubated in ice for $1 \mathrm{~h}$ followed by centrifugation at $9,200 \times \mathrm{g}$ for $15 \mathrm{~min}$ at $4^{\circ} \mathrm{C}$. The pellet containing PXR-enriched nuclear fraction was further re-suspended in electrophoresis sample buffer. To prepare the mouse liver nuclear extracts, 8-week-old mice were sacrificed by cervical dislocation and perfused with phosphatebuffered saline, as per standard methods. Then liver samples were homogenized in ice-cold PBS and centrifuged to pellet the hepatocytes. Cell pellet was resuspended in the lysis buffer $(50 \mathrm{mM}$ Tris, pH 7.4, $150 \mathrm{mM} \mathrm{NaCl,} 5 \mathrm{mM}$ EDTA, 1\% Triton X-100 and protease inhibitors cocktail as mentioned above) and incubated in ice for $1 \mathrm{~h}$ followed by centrifugation at $9,200 \times \mathrm{g}$ for $15 \mathrm{~min}$ at $4^{\circ} \mathrm{C}$. The pellet containing nuclear fraction was then resuspended in electrophoresis sample buffer. For detecting the endogenous PXR, $40 \mu \mathrm{g}$ of PXR-enriched nuclear fraction was used while to visualize the 50 $\mathrm{kDa}$ reference band (as a positive control) $2 \mu \mathrm{g}$ of whole cell extract from PXR transfected COS-1 cells was used.

Prior to Western blotting all the samples were denatured by heating at $95^{\circ} \mathrm{C}$ for $3 \mathrm{~min}$, and resolved by $10 \%$ SDS-PAGE. Proteins were transferred to polyvinyldifluori-dine (PVDF) membrane using semi-dry transfer system (BioRad). After transfer, the blot was stained with Ponceau $\mathrm{S}$ to confirm the efficiency and uniformity of protein transfer. Following transfer the membrane was blocked with $5 \%$ non-fat dry milk (powder dissolved in TBS) for $2 \mathrm{~h}$ at room temperature and then incubated with PXR antiserum at a dilution of 1: 5000 for IPTG induced E. coli cell extracts and for exogenously transfected PXR. For detecting endogenous PXR in HepG2 cells, COLO cells, COS-1 cells and mouse liver extracts antibody was used at 1:1000 dilution. Anti-His antibodies were used at a dilution of 1:10,000. Membrane with the relevant antibody was incubated over night at $4^{\circ} \mathrm{C}$. The PVDF membrane was then washed three times with TBST (TBS with $0.1 \%$ Tween-20) and incubated for $1 \mathrm{~h}$ with 1:10,000 dilution of horseradish peroxidase-conjugated antirabbit secondary antibody (Sigma). The bound antibody complexes were detected using the enhanced chemiluminescence (ECL) system.

To test the specificity of the antibody, PXR antiserum was adsorbed with excess of purified PXR and the adsorbed antiserum was used in Western blot analysis of PXR transfected COS-1 cell extract and mouse liver nuclear extracts.

\section{Immunohistological analysis of PXR in liver tissue sections}

8 -week-old mice were subjected to daily intra-peritoneal injection of $100 \mathrm{mg} / \mathrm{kg}$ of pregnenolone $16 \alpha$-carbonitrile (PCN) in olive oil plus $5 \%$ DMSO or vehicle alone for $2 \mathrm{~d}$. Four hours after the last injection, mice were sacrificed and liver samples were collected and fixed over night in $4 \%$ paraformaldehyde at $4^{\circ} \mathrm{C}$ and processed for immunohistochemical analysis as per standard methods. Briefly, formalin fixed, paraffin-embedded sections of $5 \mu \mathrm{m}$ thickness were deparaffinized with xylene and subsequently rehydrated in descending gradient of ethanol and water. Antigenic unmasking was performed by microwaving the sections in antigen retrieval solution (100 mM Glycine-HCl, and 10 mM EDTA, pH 3.0) as described previously [12-14]. Endogenous peroxidase activity was blocked by incubating sections for $10 \mathrm{~min}$ with $3 \%$ hydrogen peroxide and further non-specific background was blocked by incubating with $10 \%$ goat serum and $0.1 \%$ Triton X100 in PBS for $2 \mathrm{~h}$ at room temperature. The sections were then incubated overnight for immunodetection with PXR antiserum or pre immune serum at dilution of 1:100 at $4^{\circ} \mathrm{C}$. After three washes with PBS, sections were incubated with biotin-conjugated anti-rabbit secondary antibody (Sigma) at 1:750 dilution for $2 \mathrm{~h}$ at room temperature. After the incubation, the sections were washed three times with PBS and further incubated with anti-biotin antibodies conjugated with horseradish peroxidase (Sigma) at 1:250 dilution for $1 \mathrm{~h}$ at room temperature. After three washes with PBS the bound antibody complexes were detected using diaminobenzidine tetrahydrochloride (DAB) as a chromogen. The mouse liver sections were also stained with hematoxylin and eosin for visualization of the nuclei.

\section{RESULTS}

\section{Prokaryotic expression and purification of human PXR for immunization}

The prokaryotic expression construct pET-PXR transformed $E$. coli BL21 cells were induced with $0.1 \mathrm{mM} \mathrm{IPTG}$ for $3 \mathrm{~h}$ and the expression of His-tagged full length PXR, corresponding to molecular mass of $\sim 55 \mathrm{kDa}$ was detected by Western blot using anti-His antibodies (Fig. 1A). E.

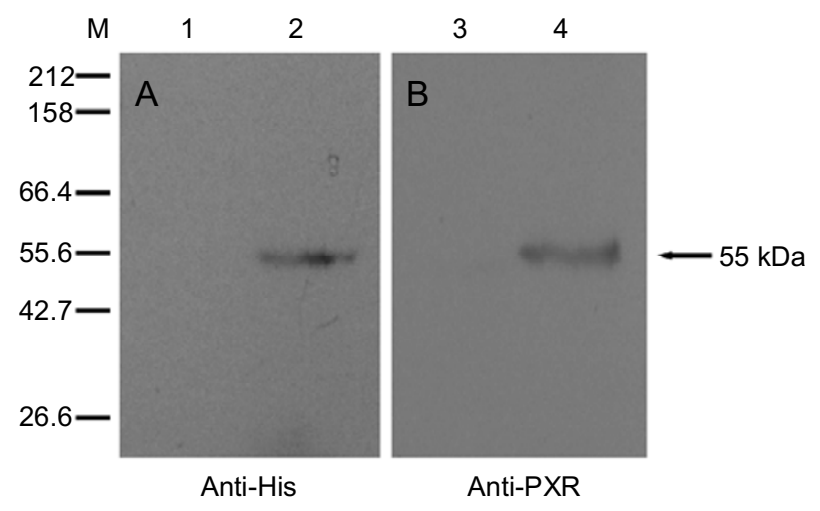

Fig. 1 Western blot analysis of $E$. coli BL21 cells expressing Histagged full length PXR protein, using anti-His (A) and anti-PXR (B) antibodies. Cell extracts were electrophoresed through 10\% SDSPAGE, blotted on to PVDF membrane and probed with the respective antibodies. A band of relative molecular weight $55 \mathrm{kDa}$ was detected in both cases. Lane 1 and 3, Uninduced bacterial cells; Lane 2 and 4, Bacterial cells induced with IPTG. Standard protein molecular weight markers (M) in $\mathrm{kDa}$ are shown on the left. 
coli BL21 cells from IPTG-induced cultures were sonicated and the majority of the PXR was found in the inclusion bodies. The fraction containing the inclusion bodies was sequentially extracted with urea extraction buffer and sarcosine extraction buffer. From the inclusion bodies, PXR could be recovered only with buffer having $\mathrm{pH}$ above 8.5. Finally, sarcosine solubilized His-PXR protein was purified by $\mathrm{Ni}^{2+}$ affinity chromatography using Ni-NTA beads. On SDS-PAGE gel the purified protein yielded a band corresponding to the expected molecular weight. Under optimized conditions, different batches of purification yielded PXR that was purified to more than $90 \%$. Under these conditions, from $2 \mathrm{~L}$ of IPTG-induced bacterial culture about $400-600 \mu \mathrm{g}$ of purified PXR was normally obtained that was sufficient for each immunization step. Though a near homogeneous preparation of PXR protein was clearly evident we preferred to inject the protein after excising the $\mathrm{KCl}$ stained band from polyacrylamide gel. Electrophoresed PXR band corresponding to 55 $\mathrm{kDa}$ could be exclusively excised from the gel and homogenized for use. For primary injection and corresponding booster injections the purity and recovery of gel-excised band was always reconfirmed (Fig. 2). Therefore, a homogenized preparation containing a single protein for PXR could be confidently used for immunizing the New Zealand White rabbit. The antiserum was collected $15 \mathrm{w}$ after the first injection and subsequent three boosters. At

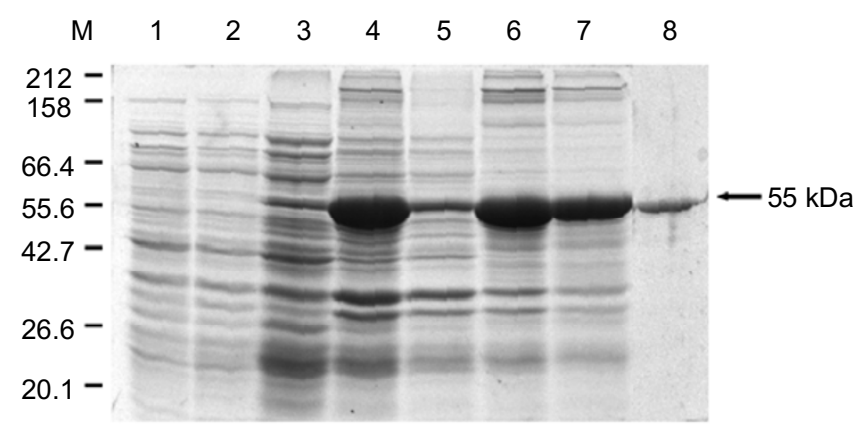

Fig. 2 A typical SDS-PAGE profile of PXR expressed and purified from E. coli BL21.Lane 1, Uninduced E. coli BL21 cells; Lane 2, IPTG induced E. coli BL21 cells; Lane 3, Supernatant fraction from IPTG induced cells, after sonication; Lane 4, Pelleted fraction from IPTG induced cells, after sonication; Lane 5, Supernatant fraction of inclusion bodies after extraction with urea extraction buffer; Lane 6 , pelleted fraction of inclusion bodies after extraction with urea extraction buffer; Lane 7, Supernatant fraction of urea extracted inclusion bodies after solubulizing in sarcosine extraction buffer; Lane 8, PXR was purified using Ni-NTA-column chromatography of the sample described in lane 7. This purified sample was extracted from homogenized gel slice and used as antigen. ' $\mathrm{M}$ ' indicates the standard protein markers in $\mathrm{kDa}$.

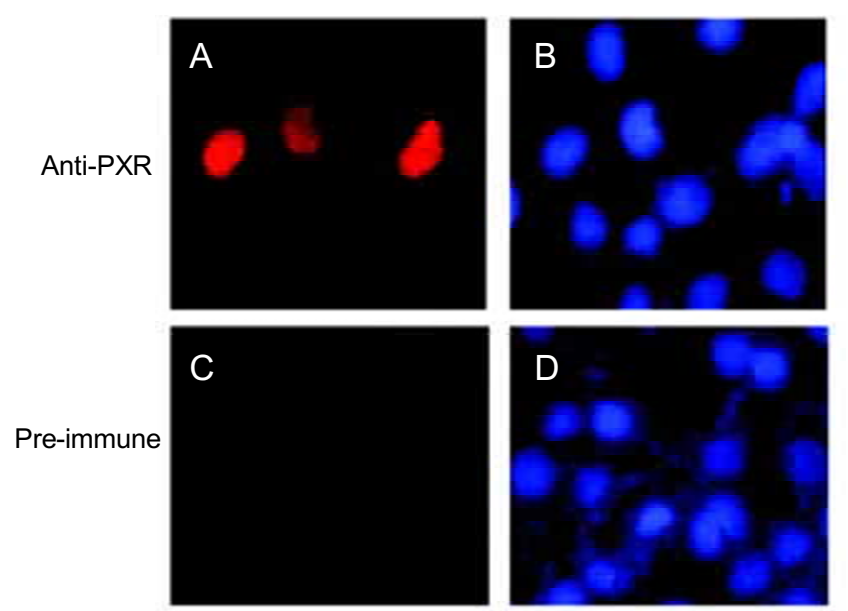

Fig. 3 Indirect immunofluorescence staining of COS-1 cells transfected with hPXR plasmid. COS- 1 cells were transiently transfected with hPXR and after $24 \mathrm{~h}$ of expression, the cells were fixed, processed for immunodetection with anti-PXR antibodies (A and $\mathbf{B}$ ) or preimmune serum ( $\mathbf{C}$ and $\mathbf{D}$ ) and imaged as described under 'Materials and Methods'. The left panel shows the distribution patterns of receptor in immunodetected cells. The right panel shows the Hoechst staining for visualizing the nuclei.

1:5000 dilution His-tagged PXR protein of $55 \mathrm{kDa}$ was detected in Western blot analysis, using IPTG induced $E$. coli BL21 cell extract. With the uninduced cells no immunoreactivity was observed (Fig. 1B).

\section{Detection of PXR in transfected mammalian cells in culture}

To address the question as to whether antiserum could detect exogenously transfected PXR in cultured mammalian cells, COS-1 cells were transiently transfected with the hPXR plasmid and the expressed protein was detected by indirect immunofluorescence staining. The results with transfected cells showed a predominant nuclear localized PXR with immune serum while no staining was observed with preimmune serum from the same animal (Fig. 3).

As a test of the identity of the PXR protein and specificity of PXR antibodies Western blot analyses were undertaken. Cell extracts from hPXR transfected COS-1 cells were prepared after $0,10,20,30$ and $40 \mathrm{~h}$ of transfection period and analysed by Western blot (Fig. 4). A time dependent increase in the specific immuno-reactivity of a major protein band having an expected molecular weight of PXR $(\sim 50 \mathrm{kDa})$ was detected along with gradual increase of four other less prominent protein bands. Only one of these immunodetected protein bands had a molecular weight above $50 \mathrm{kDa}$ while other three were below 


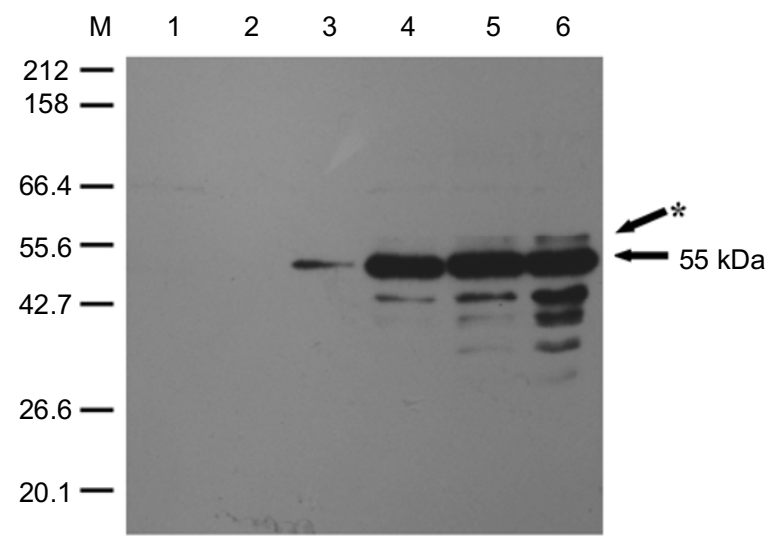

Fig. 4 Western blot analysis of the COS-1 cells transfected with $\mathrm{hPXR}$ and expressing the protein over varied time period. Cell extracts were prepared after $0,10,20,30$ and $40 \mathrm{~h}$ of transfection and electrophoresed through $10 \%$ SDS-PAGE, blotted on to PVDF membrane and probed with anti-PXR antibodies at a 1:5000 dilution. Lane 1, Untransfected COS-1 cells extract, no band was detected; Lane 2, Cell extract prepared at $0 \mathrm{~h}$ after transfection; Lane 3, Cell extract prepared $10 \mathrm{~h}$ after transfection; Lane 4, Cell extract prepared $20 \mathrm{~h}$ after transfection; Lane 5, Cell extract prepared $30 \mathrm{~h}$ after transfection; Lane 6, Cell extract prepared $40 \mathrm{~h}$ after transfection; A gradual increase in the specific reactivity with a major protein band having molecular weight of 50kDa was detected. The significance of lower molecular weight bands detected by the same antiserum is discussed in the text. A faint band above $50 \mathrm{kDa}$ (indicated with an asterisk) was also detectable. ' $\mathrm{M}$ ' indicates position of standard protein markers in $\mathrm{kDa}$.

$50 \mathrm{kDa}$ size. These immunodetected bands were a consequence of PXR transfection since no such bands were detectable in untransfected COS-1 cells. Also, under similar experimental conditions, no band was highlighted when immune serum was replaced with pre-immune serum obtained from the same rabbit (data not shown). Such band profile appearing below $50 \mathrm{kDa}$ will normally be considered to be a consequence of intracellular events like proteasomal degradation. However, in the context of a recent report where Glucocorticoid Receptor (GR) was expressed in COS-1 cells with similar results $[15,16]$ the possibility that these PXR bands may be isoforms cannot be excluded.

Being a transcription factor, PXR binds to the specific responsive elements in the enhancer region of its regulated genes. Therefore, we further investigated whether the antiserum could recognize PXR-DNA protein complex by EMSA. For this assessment, COS- 1 cells were transiently transfected with hPXR plasmid and the crude cell extracts were used as a protein source in our EMSA studies. The probe containing everted repeat- 6 sequence (ER-6) from CYP3A4 promoter was used [1]. To estab- lish the specificity of binding of PXR to ER-6 sequence, competitor oligonucleotides i.e., either cold wild type or cold mutated oligonucleotides were added to the reaction mix in 100,150 or 200 fold molar excess. From our observations it was apparent that radio-labelled DNA-PXR complex was depleted by presence of excess of cold wild type probe (Fig. 5, lane 3, 4 and 5) but not in presence of excess molar of cold mutated probe (Fig. 5, lane 6,7 and 8). Purified anti-PXR immunoglobulins interacted specifically with the PXR-DNA complex as evident from its disappearance from its original position (Fig. 5, lane 9). Conversely, preimmune immunoglobulins (control) did not impart similar effect on PXR-DNA complex (Fig. 5, lane 10) implying that PXR antibody can be effectively used in EMSA.

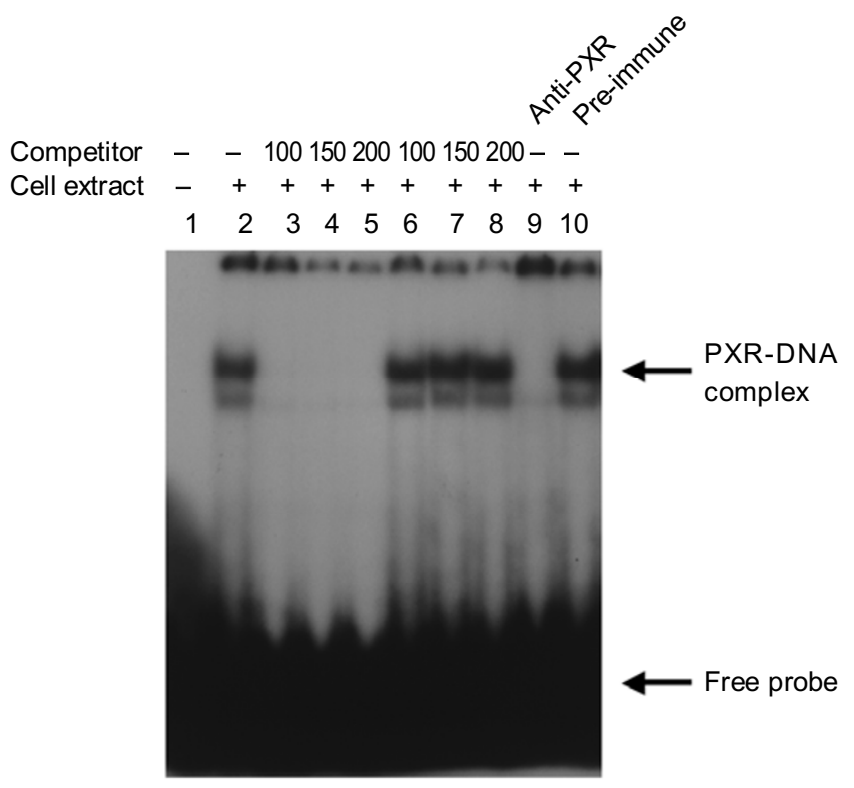

Fig. 5 PXR antibody interacts specifically with PXR-DNA complex in EMSA. COS-1 cells were transiently transfected with hPXR and after $24 \mathrm{~h}$ of expression, whole cell lysate was prepared as described under 'Materials and Methods'. $1 \mu \mathrm{g}$ of whole cell extract was incubated with $0.5 \mathrm{ng}$ of $30 \mathrm{bp}$ Klenow end labeled oligonucleotide probe and the complexes thus formed were resolved on a $5 \%$ polyacrylamide gel and autoradiagraphed as mentioned in 'Materials and Methods'. No complex was detected with probe alone (Lane 1). A single DNA-protein complex was detected in PXR transfected COS1 cell extract (Lane 2 ). The complex was efficiently competed by a specific competitor oligonucleotide probe (CYP3A4 ER-6) (Lane 3, 4 and 5) but not by non-specific competitor oligonucleotide probe (CYP3A4 ER-6 mutant) (Lane 6, 7 and 8) at 100 (Lane 3 and 6), 150 (Lane 4 and 7) and 200 (Lane 5 and 8) fold molar excess. Addition of $2 \mu \mathrm{g}$ of purified PXR immunoglobulins resulted in disappearance of the PXR-DNA complex from its original position (Lane 9), while control (preimmune) immunoglobulins failed to produce this specific effect (Lane10). 


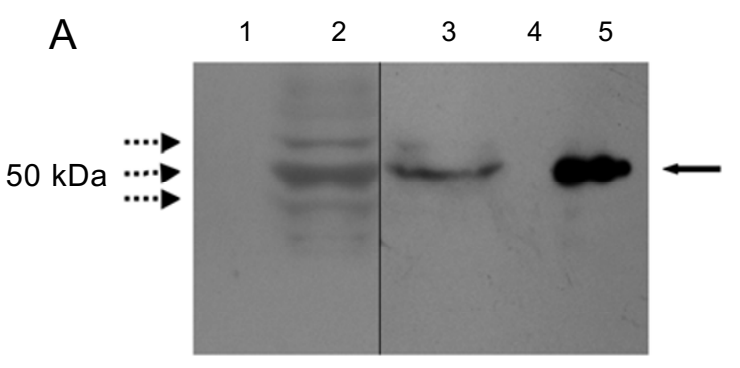

B

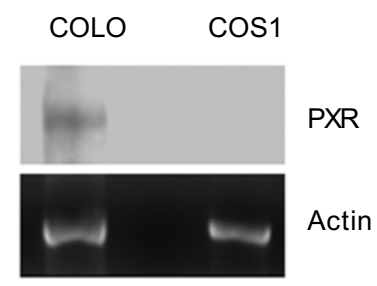

Fig. 6 (A) Western blot analysis of endogenous PXR protein in COS-1, HepG2 and COLO cell lines using anti-PXR antibodies at a 1:1000 dilution. Nuclear extracts from COS-1, HepG2 and COLO cells were prepared, electrophoresed through $10 \%$ SDS-PAGE, blotted on to PVDF membrane and probed with anti-PXR antibodies as described in 'Materials and Methods'. A major band of relative molecular weight $50 \mathrm{kDa}$ was detected. As in the case of PXR transfected COS-1 cells, an endogenous protein above $50 \mathrm{kDa}$ was also detectable in HepG2 and COLO cells. In HepG2 a band below $50 \mathrm{kDa}$ was also detected. These bands are shown in the figure by broken arrows. No bands were immunodetected in untransfected COS-1 cell extract. Lane 1, Untransfected COS-1 cells nuclear extract; Lane 2, HepG2 cells nuclear extract; Lane 3, COLO cells nuclear extract; Lane $4,1 \times$ SDS PAGE sample buffer without proteins; Lane 5, PXR transfected COS-1 cell extract.(B) Detection of PXR mRNA in COLO and COS-1 cells. Top: Total RNA from COLO and COS-1 cells were extracted and 'radiolabelled RT-PCR' was performed as described under 'Materials and Methods'. PCR amplification products were resolved on $5 \%$ polyacrylamide gel and autoradiographed. Amplification yielded expected $410 \mathrm{bp}$ fragment in COLO cells. No band was detected in COS-1 cells. Bottom: RTPCR amplification of $\alpha$-Actin mRNA from COLO and COS- 1 cells. PCR amplification products were resolved on $2 \%$ agarose gels and visualized by ethidium bromide staining. Amplification yielded expected $614 \mathrm{bp}$ fragment in COLO and COS-1 cells.

\section{Detection of endogenous PXR in cultured mamma- lian cell lines and mouse liver tissue sections}

From the earlier reports with RT-PCR and Northern blotting approaches, PXR levels are reported to be relatively higher in liver and intestinal tissues when compared with the other tissues [3, 7]. Also, endogenous levels of PXR protein in cultured mammalian cell lines appear to be significantly low. Undetectable levels in whole cell extracts from a liver cell line, HepG2, have been reported recently [17]. But with the use of radio-labeled nucleotides in RT-
PCR, PXR transcript was detected in HepG2 [18] and in several breast cancer cell lines [9]. Hence, to detect the PXR transcript expression in COLO and COS-1 cells we used similar radio-labeling RT-PCR approach. Our results revealed an expected $410 \mathrm{bp}$ amplicon of PXR in COLO cells but not in the COS-1 cells (Fig. 6B). Recently, Gardner-Stephen et al [19] using RT-PCR based approaches have shown three variants of PXR that are expressed in liver and intestinal mucosa. Hence, using PXR antiserum we also investigated the expression of PXR variants in a liver cell line (HepG2) and intestinal adenocarcinoma cell line (COLO) by Western blot analysis. Based on this study, as well as others [20], transfected PXR is observed to be a predominantly nuclear protein. Therefore, we prepared PXR-enriched nuclear extract from cultured cells for our Western blot analyses. In HepG2 cells nuclear extract three major bands that corresponded to the bands in the PXR transfected COS- 1 cells ( $40 \mathrm{~h}$ transfection) were highlighted (Fig. 6A, lane 2). In COLO cells extract, a specific band that corresponded to $50 \mathrm{kDa}$ PXR of transfected COS-1 cells (positive control) was highlighted (Fig. $6 \mathrm{~A}$, lane 3). Also, a second faint band above $50 \mathrm{kDa}$ corresponding to the one in transfected COS-1 was also evident. These bands were not detectable when pre immune serum was used (not shown). Since the band profile from HepG2 and COLO nuclear extracts compared well with corresponding bands in transfected positive control, these are assumed to be endogenous PXR. The possibility that higher molecular band may be indicative of a fraction of PXR protein that has undergone post-translational modifications is not ruled out. When probed with PXR antibodies this band was absent in prokaryotic $E$. coli cell lysates (Fig. 1B) since post-translational modification events that are exclusive to mammalian cells are unlikely to occur in bacteria. The exact nature of this band needs to be investigated.

To further confirm the efficacy of our PXR antibodies, we attempted immunohistological studies with the mouse liver tissue sections. At first, cross-reactivity of hPXR antiserum to $\mathrm{mPXR}$ was confirmed by immunodetecting the transiently transfected mPXR in COS- 1 cells. The results in Fig. 7A show that the mouse PXR was detectable in cell nuclei with the antibody raised against the full length human PXR. For Western blot analysis mPXR and hPXR were independently transfected in COS- 1 cells and allowed to express the receptor for $20 \mathrm{~h}$ as described in Fig 4. As shown in Fig. 7B, the mouse PXR band corresponded with the human PXR band at $50 \mathrm{kDa}$ position. In terms of sequence homology mouse PXR protein shares $77 \%$ homology with human PXR. Hence, presence of common epitopes between the two species recognised by this antibody is not surprising. No immune reactivity was observed 
A

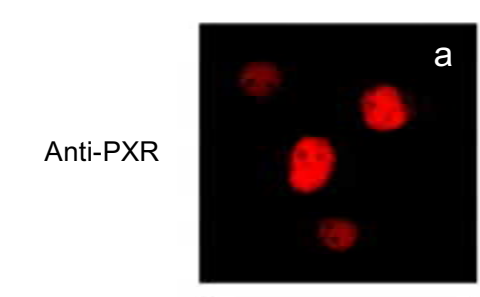

Pre-immune

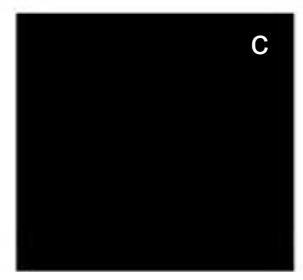

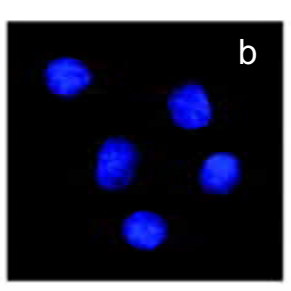

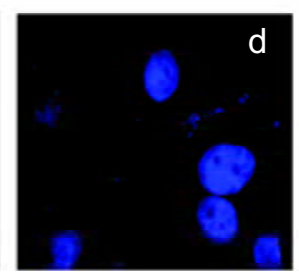

B

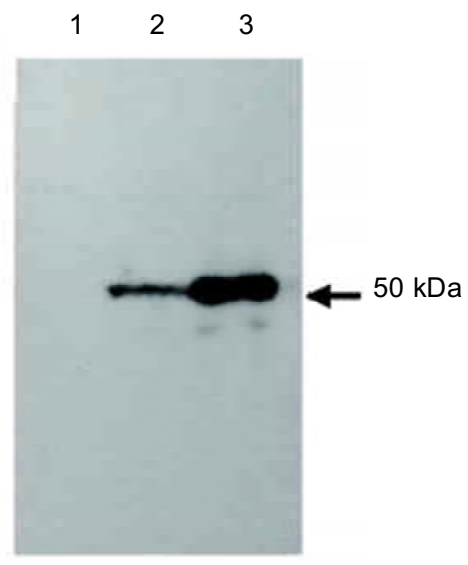

Fig. 7 (A) Human PXR antibody cross-reacts with mouse PXR. Indirect immunofluorescence staining of COS-1 cells transfected with mouse PXR. COS-1 cells were transiently transfected mPXR and after $24 \mathrm{~h}$ of expression, the cells were fixed, processed for immunodetection with anti-PXR antibodies ( $a$ and b) or preimmune serum (c and d) and imaged as described under 'Materials and Methods'. The left panel shows the distribution patterns of receptor in immunodetected cells. The right panel shows the Hoechst staining for visualizing the nuclei. (B) Western blot analysis of the COS-1 cells transfected with mouse PXR. COS-1 cells were transiently transfected with $\mathrm{mPXR} / \mathrm{hPXR}$ and after $20 \mathrm{~h}$ of expression cell extracts were prepared and electrophoresed through $10 \%$ SDS-PAGE, blotted on to PVDF membrane and probed with anti-PXR antibodies at a 1:5000 dilution. Lane 1, Untransfected COS1 cells extract, no band was detected; Lane 2, mPXR transfected COS-1 cells extract, a band of relative molecular weight $50 \mathrm{kDa}$ was detected; Lane 3, hPXR transfected COS-1 cells extract, a band of relative molecular weight $50 \mathrm{kDa}$ was detected.

with preimmune serum.

The utility and specificity of PXR antiserum was established by immunodetecting the endogenous PXR in the mouse liver nuclear extracts by Western blot analysis. Three major bands ( $\sim 50 \mathrm{kDa}$ and above) and three minor bands (below $50 \mathrm{kDa}$ ) were visible (Fig. 8A, lane 3) and some of these bands appeared to correspond with the COS-1 cells transfected with human PXR (Fig. 8A, lane 1). Adsorption of immune serum with excess of purified PXR antigen prevented immune reactivity with these bands, which further confirmed the specificity of antibody for the highlighted bands (Fig. 8B). Antigenic epitope unmasking appears to be one of the critical factors that govern the development of signal in immunohistochemistry [12-14]. Hence, we used a series of target antigen retrieval buffers (Glycine-HCl buffer $\mathrm{pH}$ 3.0, Citrate buffer $\mathrm{pH} 6.0$ and Tris buffer $\mathrm{pH}$ 9.0, along with $10 \mathrm{mM}$ EDTA) during micro-waving the tissue sections. Enhanced nuclear stain deposition was observed only with Glycine- $\mathrm{HCl}$ buffer $\mathrm{pH}$ 3.0. Under optimum conditions, a modest level of PXR was detectable in mouse liver tissue sections. For further studies, liver tissue sections derived from PCN treated mice and corresponding control (vehicle treated) were also used. Our results showed that PXR localized in the nuclei of liver tissue cells irrespective of the PCN treatment (Fig.
9). Although cellular localization of PXR has been controversial with respect to its nuclear or cytoplasmic residency, our results using the PXR antibody indicated its localization to be nuclear in PCN treated and untreated mice. It is reasonable to speculate that under in vivo situations, localization of normal PXR should be nuclear due to its interactions with diverse range of endogenous ligands (steroids, bile acids, cholesterol and other endogenous metabolites) circulating in the body fluid.

Taken together, our results indicate that the antiserum raised against the full length PXR is highly specific and due to the possibility of recognizing many epitopes on a single PXR antigen, it can detect significantly lower levels of PXR protein that is expressed endogenously or by transient transfection in the mammalian cell lines.

\section{DISCUSSION}

PXR, a ligand activated transcriptional factor, regulates a network of genes that in turn play an important role in protecting the body against chemical insult. Hence, PXR appears to function as a 'biosensor' in recognizing and clearing the endobiotics as well as xenobiotics from the body. In recent reports, PXR has been shown to be present in various normal tissues, including liver, small intestine, colon, skeletal muscle, stomach, testes, trachea, kidney, 
adrenal gland and thyroid gland etc [7]. Due to lack of PXR specific antibodies that could detect low levels of endogenously expressed PXR, these studies mainly relied on either Northern blot or RT-PCR analysis. Although a few antibodies against the PXR protein are currently available, these have been raised against specific epitopes present on the antigen, PXR. Results obtained from the use of antibodies are as good as the antibodies themselves. Hence, when put to test, different qualities of antibodies will produce different or conflicting data.

PXR has been shown to be present exclusively in nuclei of endometrial cancer tissues or predominantly in nucleus and weakly in cytoplasm of the oral contraceptive-exposed endometrium [8]. Conversely, the mouse ortholog of hPXR cloned and expressed with a tag is reported to be localized

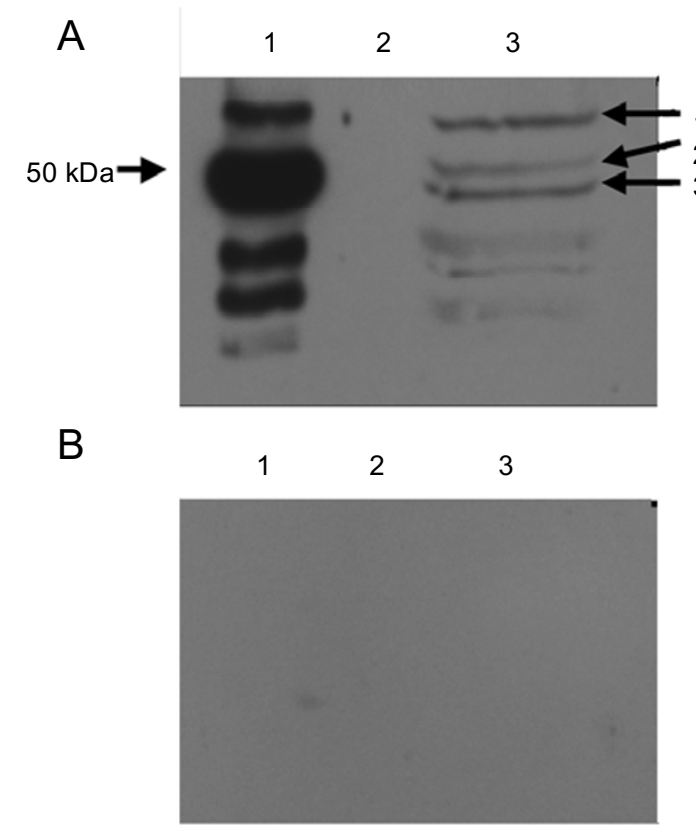

Fig. 8 (A) Western blot analysis of endogenous PXR in mouse liver nuclear extract, using anti-PXR antibodies at 1:1000 dilution. Mouse liver nuclear extract was prepared, electrophoresed through $10 \%$ SDS-PAGE, blotted on to PVDF membrane and probed with antiPXR antibodies as described in 'Materials and Methods'. Lane1, PXR transfected COS-1 cell extract, a major $50 \mathrm{kDa}$ is visible (indicated by an arrow); Lane 2, sample buffer; Lane 3, In mouse liver nuclear extract three major bands (indicated by arrows) and also three minor bands are visible. (B) Western blot analysis of endogenous PXR in mouse liver nuclear extract, using adsorbed anti-PXR antibodies at 1:1000 dilution. Mouse liver nuclear extract was prepared, electrophoresed through $10 \%$ SDS-PAGE, blotted on to PVDF membrane and probed with anti-PXR antibodies as described in 'Materials and Methods'. Lane1, PXR transfected COS-1 cell extract; Lane 2, sample buffer; Lane 3, Mouse liver nuclear extract.
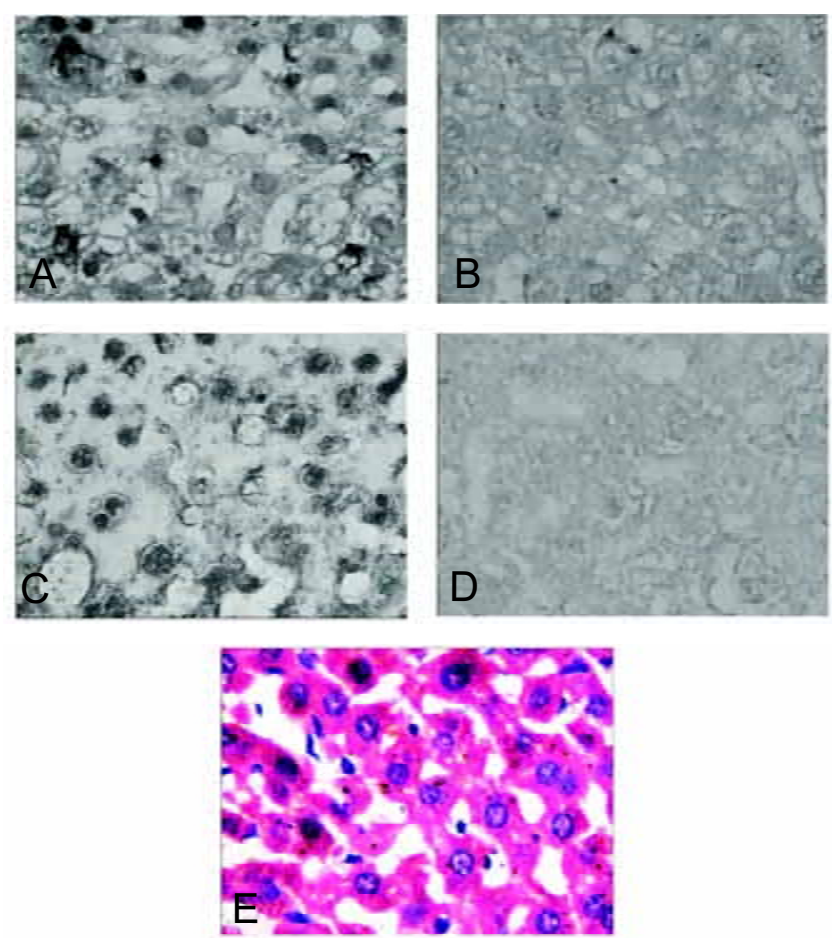

Fig. 9 Immunohistochemical analysis of PXR in mouse liver tissue sections. Formalin-fixed, paraffin-embedded tissue sections from vehicle-treated (A and $\mathbf{B}$ ) or PCN treated (C and $\mathbf{D})$ were processed for immunohistology as described under 'Materials and Methods' and incubated with PXR antiserum (A and $\mathbf{C}$ ) or preimmune serum (B and $\mathbf{D}$ ) at 1:100 dilution. Immunostaining was performed as described under 'Materials and Methods', using DAB as a chromogen. A liver tissue section stained with hematoxylin and eosin is shown in $\mathbf{E}$.

in the cytoplasm of mouse liver cells [21]. Furthermore, endogenously expressed PXR protein has been shown to be localized in cytoplasm of cultured HepG2 cells [21] while it was undetectable in same cell line by other group [17]. When expressed by transfection in cultured cells, ligand-independent nuclear localization was observed [20, $22]$. On the other hand, 'nuclear extracts' that were prepared from untreated adult male Wistar rats offered nuclease protection in DNase I foot print analysis of rifampicin-responsive region. A similar pattern of nuclease protection was observed with nuclear extracts prepared from untreated and rifampicin treated HepG2 cells [23]. All these studies used PXR-enriched 'nuclear extracts' implying its presence in the nucleus. Therefore, receptor presence or localization data from a range of experiments (footprint analysis, immunocytochemistry, immunoprecipitation and detection of tagged receptor in fixed and live cells) have all encountered contradictory results. To resolve this issue, we purified the full-length PXR and raised antibodies 
against it. This approach of raising antibody against a fulllength protein has an advantage over the ones that were raised against peptides. When raised against whole protein many more epitopes are available for eliciting immune response, and a single PXR protein (antigen) will bind more IgG molecules making the immunodetection more sensitive. Also, the fear of an epitope being buried could be minimized since many alternative epitopes will be available. If a chosen peptide lacks uniqueness for PXR, there might be higher chances for cross-reactivity with other proteins. However, when dealing with antibody quality, circumstantial advantages and disadvantages from either of the two approaches cannot be totally ruled out. In the present work we seem to have overcome some of such constraint, as the PXR antibody raised in our laboratory appears to be specific and also sensitive in detecting lower levels of endogenous PXR protein.

To produce the polyclonal antiserum, homogenized polyacrylamide gel slice containing purified recombinant PXR protein was used as the immunogen. This eliminated the possibility of inducing any immune response to any highly antigenic bacterial protein contaminant that could be present in our apparently purified PXR preparation. The polyclonal antiserum detected the PXR specifically when this protein was expressed in $E$. coli, indicating that the antiserum is capable of recognizing the PXR protein when expressed in a prokaryotic system. Western blot analysis of exogenously transfected PXR in COS-1 cells and endogenously expressed PXR in HepG2 and COLO cells consistently revealed a $50 \mathrm{kDa}$ protein band along with other bands that could be PXR isoforms. In case of human and rat, three main bands have been previously reported in experiments utilizing in vitro transcription-translation approach. Of the three bands reported, one was larger and the other was smaller in size with respect to the major $50-51 \mathrm{kDa}$ band $[1,24]$. Recently, in case of another nuclear hormone receptor, i.e., human GR, eight isoforms for GR have been reported $[15,16]$. Evidences have been obtained that indicate that multiple GR isoforms may be generated from one single GR gene via alternative translation initiation, transcript alternative splicing and mutations and/ or polymorphisms. Analogous to our observation they have documented eight isoforms for GR when GR construct was transfected and expressed in COS- 1 cells. Whether processes reported in case of GR also generate the PXR isoforms awaits detailed investigation. The possibility that presence of different PXR isoforms in different tissues and cells may utilize combinatorial mechanisms to regulate different sets of genes under varied physiological or pathogenic conditions should be a focus of research in near future.

Immunofluorescence staining of the COS- 1 cells trans- fected with untagged PXR showed clear nuclear localization of PXR. Results from immunohistology revealed that the level of PXR in liver is immunologically detectable in the nuclei of hepatocytes. Taken together, these results are strongly supporting that the antiserum is highly specific against PXR in experiments dealing with immunocytology, Western blot, EMSA and immunohisto-chemistry. Availability of this PXR antibody could facilitate the functional characterization of PXR in normal and malignant conditions.

\section{ACKNOWLEDGEMENTS}

The research work presented in this paper was financially supported by research grants to RKT from Indian Council of Medical Research (ICMR) and Council of Scientific and Industrial Research (CSIR), India. ICMR (NET) fellowship to MS and ICMR project fellowship to BK are gratefully acknowledged. Human and mouse PXR constructs were generous gifts from Dr. RM EVANS (Salk Institute, La Jolla, CA), Dr. SA KLIEWER (University of Texas Southwestern Medical Center, Dallas, USA) and Dr. M NEGISHI (National Institute of Health, North Carolina, USA). We are thankful to members of Prof. K DATTA lab for help with immunohistology experiments.

\section{Received, Apr 1, 2005}

Revised, Sep 12, 2005

Accepted, Oct 12, 2005

\section{REFERENCES}

1 Lehmann JM, McKee DD, Watson MA, et al. The human orphan nuclear receptor PXR is activated by compounds that regulate CYP3A4 gene expression and cause drug interactions. J Clin Invest 1998; 102:1016-23.

2 Kliewer SA, Moore JT, Wade L, et al. An orphan nuclear receptor activated by pregnanes defines a novel steroid signaling pathway. Cell 1998; 92:73-82.

3 Blumberg B, Sabbagh WJr, Juguilon H, et al. PXR, a novel steroid and xenobiotic-sensing nuclear receptor. Genes Dev 1998; 12:3195-205.

4 Bertilsson G, Heidrich J, Svensson K, et al. Identification of a human nuclear receptor defines a new signaling pathway for CYP3A induction. Proc Nat Acad Sci U S A 1998; 95:12208-13.

5 Kliewer SA, Goodwin B, Willson TM. The nuclear pregnane X receptor: a key regulator of xenobiotic metabolism. Endocr Rev 2002; 23:687-702.

6 Rosenfeld JM, Vargas RJr, Xie W, Evans RM. Genetic profiling defines the xenobiotic gene network controlled by the nuclear receptor pregnane X receptor. Mol Endocrinol 2003; 17:1268-82.

7 Nishimura M, Naito S, Yokoi T. Tissue-specific mRNA expression profiles of human nuclear receptor subfamilies. Drug Metab Pharmacokinet 2004; 19:135-49.

8 Masuyama H, Hiramatsu Y, Kodama J, Kudo T. Expression and potential roles of pregnane $\mathrm{X}$ receptor in endometrial cancer. $\mathrm{J}$ Clin Endocrinol Metab 2003; 88:4446-54. 
9 Dotzlaw H, Leygue E, Watson P, Murphy LC. The human orphan receptor PXR messenger RNA is expressed in both normal and neoplastic breast tissue. Clin Cancer Res 1999; 5:2103-7.

10 Synold TW, Dussault I, Forman BM. The orphan nuclear receptor SXR coordinately regulates drug metabolism and efflux. Nat Med 2001; 7:584-590.

11 Takami N, Sakamoto H, Yamamoto T. Steroid and xenobiotic receptor (SXR) is a key system for the acquisition of cisplatin resistance in endometrial cancer cells. J Int Med Res 2003; 31: $59-68$.

12 Shi SR, Key ME, Kalra KL. Antigen retrieval in formalin-fixed, paraffin-embedded tissues: an enhancement method for immunohistochemical staining based on microwave oven heating of tissue sections. J Histochem Cytochem 1991; 39:741-8.

13 Shi SR, Imam SA, Young L, Cote RJ, Taylor CR. Antigen retrieval immunohistochemistry under the influence of $\mathrm{pH}$ using monoclonal antibodies. J Histochem Cytochem 1995; 43:193-201.

14 Taylor CR, Shi SR, Chaiwun B, et al. Strategies for improving the immunohistochemical staining of various intranuclear prognostic markers in formalin-paraffin sections: androgen receptor, estrogen receptor, progesterone receptor, $\mathrm{p} 53$ protein, proliferating cell nuclear antigen, and Ki-67 antigen revealed by antigen retrieval techniques. Hum Pathol 1994; 25:263-70.

$15 \mathrm{Lu} \mathrm{NZ}$, Cidlowski JA. The origin and functions of multiple human glucocorticoid receptor isoforms. Ann N Y Acad Sci 2004; 1024:102-23.

16 Lu NZ, Cidlowski JA. Translational regulatory mechanisms generate $\mathrm{N}$-terminal glucocorticoid receptor isoforms with unique transcriptional target genes. Mol Cell 2005; 18:331-42.

17 Lemaire G, Sousa Gde, Rahmani R. APXR reporter gene assay in a stable cell culture system: CYP3A4 and CYP2B6 induction by pesticides. Biochem Pharmacol 2004; 68:2347-58.

18 Kauffmann HM, Pfannschmidt S, Zoller H, et al. Influence of redox-active compounds and PXR-activators on human MRP1 and MRP2 gene expression. Toxicology 2002; 171:137-46.

19 Gardner-Stephen D, Heydel JM, Goyal A, et al. Human PXR variants and their differential effects on the regulation of human UDP-glucuronosyltransferase gene expression. Drug Metab Dispos 2004; 32:340-7.

20 Kawana K, Ikuta T, Kobayashi Y, et al. Molecular mechanism of nuclear translocation of an orphan nuclear receptor, SXR. Mol Pharmacol 2003; 63:524-31.

21 Squires EJ, Sueyoshi T, Negishi M. Cytoplasmic localization of pregnane $\mathrm{X}$ receptor and ligand-dependent nuclear translocation in mouse liver. J Biol Chem 2004; 279:49307-14.

22 Echchgadda I, Song CS, Oh TS, et al. Gene regulation for the senescence marker protein DHEA-sulfotransferase by the xenobiotic-activated nuclear pregnane X receptor (PXR). Mech Ageing Dev 2004; 125:733-45.

23 Goodwin B, Hodgson E, Liddle C. The orphan human pregnane $\mathrm{X}$ receptor mediates the transcriptional activation of CYP3A4 by rifampicin through a distal enhancer module. Mol Pharmacol 1999; 56:1329-39.

24 Zhang H, LeCulyse E, Liu L, et al. Rat pregnane X receptor: molecular cloning, tissue distribution, and xenobiotic regulation. Arch Biochem Biophys 1999; 368:14-22.

Edited by Zhong Cheng ZHENG 